\title{
Interview
}

\section{Automating creative and advertising workflows at Newsday- An interview with James Kober of Newsday}

\section{James Kober}

has been working at Newsday for 19 years, during which time he moved up from an entry-level position in the ad layout department to ad operator and imaging technician, and now is a prepress area manager. Newsday constitutes America's sixth largest regional newspaper, publishing both in print and online.

\begin{abstract}
Michael Moon of GISTICS interviews James Kober, prepress area manager for Newsday, and Vince Di Paolo of Moksa, examining ad operations workflow in the newspaper industry in general and at Newsday, specifically. The interview investigates how Newsday used Canto Cumulus to stimulate creative collaboration, streamline production between print and online groups, support field sales, and drive process innovations and faster cycle times.
\end{abstract}

Journal of Digital Asset Management (2009) 5, 237-245. doi:10.1057/dam.2009.15

Keywords: DAM-enabled workflow; ad operations; adobe creative suite; prepress; creative workflow

\section{BACKGROUND}

MM: We're here with James Kober of Newsday. Let's start off with a little bit of background, your current position and a little bit of your career highlights.

JK: My name is James Kober, and my current job title at Newsday is prepress area manager.

I've been with the company almost 19 years. I went to Queens College in the City University of New York system. I was looking for a job right after school. I came to Newsday and I took an entry-level job.

I've been through various jobs from clerking in the ad layout department to actually honing my prepress skills and becoming an ad operator/ imaging technician and an assistant supervisor. I've worked my way up to the point where I now am supervising 144 people.

I have all of Newsday's prepress/ad layout folks

Correspondence: James Kober Newsday, 235 Pinelawn Road, Melville, NY 11747, USA E-mail: james.kober @ newsday.com from the front end - interactive or print - all the way up to output to plate. I also have the Newsday subsidiary, Star Publishing. They produce 183 weeklies.

So there's a little bit about my background.

\section{NEWSDAY MEDIA GROUP}

MM: Would you give us a little bit of an overview of Newsday as an organization - the approximate size, number of employees and information like that?

JK: The Newsday Media Group, as they now like to be known, now has about 2200 employees. It started out in a garage, in Garden City - 60-some odd years ago. It was 1940. Newsday was founded by Alicia Patterson. Her father ran the Daily News.

Obviously, the last several years, there's been a sea change in the newspaper industry. Folks are moving more and more toward the Web to get their news. People are very busy in their lives - finding less time to read the newspaper.

But the recent encouraging and exciting news is that Newsday was purchased by Cablevision - the sixth largest cable operator in the country. That deal was closed approximately three and a half months ago. Everyone here is hopeful that with Cablevision's programming and advertising structure, we can cover all of 
our customers' needs between print, online and television.

So we're excited about the future, and we're just starting to move into that area, right now.

\section{AD OPERATIONS}

MM: Could you describe a little more of what goes on in terms of ad operations - both in terms of the clients, the advertisers that you serve and the kinds of ads that your operations produce?

JK: We serve any and all advertisers. If we have a small business on Long Island, and they need help building their ad, they don't have to pay an agency. We certainly will do that for them. It's part of the price of the ad. Then we'll do campaigns and we'll put together presentations for someone like Target - which we did last year.

We literally go from the small local retailers all the way up. We'll do work for the national folks if they want us to get involved with helping them.

We have a full creative staff, and any creative needs of the company on the advertising side are handled by that group. Then we have a full production staff. So they'll handle any of the production needs that arise when customers send in their digital files.

\section{NEWSPAPER INDUSTRY TRANSFORMATIONS}

MM: You talked about how publishing in general and newspapers in particular continue to undergo significant structural changes to their business models and sources of revenue. Could you expand upon some of those changes and how digital technology continues to provide a platform for innovating and driving some of those changes or addressing some of those market forces?

JK: Sure. Historically, when we would work an ad that would appear in print, it would be very common to work the ad, make paper proofs, and have the sales representative - the account executive - swing by and pick up the proof to take out to the client.

Through digital technology, we have taken that to the next level. Using a system like Canto Cumulus, we can work the ad and publish it. Then instead of us having to make paper proofs and have a sales representative swing by to pick that up and take it to the client, the sales assistant who's in the building can log into the Cumulus system via a Web client. They can search on the client name and look at the proof themselves. From there, we can email it to the client or the account executive - whoever wants it.

\section{CONSULTANT'S SUMMARY OF WORKFLOW}

MM: Vince, as the lead consultant on the project, would you give a quick survey of how this works?

VDP: First, the graphic artist ingests the newly created ad into Cumulus. When they are ready to have the ad reviewed, they simply select the Publish to PDF option from a custom Moksa-created menu. This triggers a process that sends the ad through an approval process that first creates a PDF of the file and then publishes it to a Web catalog. An email is then generated by the system, addressed to appropriate sales and clients needing to approve the ad. The email contains a link that logs the user into the Web catalog, and places them right at the ad review screen. Here it can be approved or edited comments can be collected for modification requirements. If edits are necessary, the comments will be collected and forwarded to the graphic designer, together with a link to the original InDesign document, via email. This loop may continue until the ad is approved.

JK: The digital revolution has certainly streamlined the process, and truly benefits our customers by getting them what they need faster, and giving them more time to make any necessary changes that they may need. Taking that a step further - let's get away from print and talk about interactive and video for a moment. Everyone seems to be very excited about the potential for video.

In the past, I guess you'd have to have a client in to do the presentation or work hard to get an artist to go out and visit the client, possibly.

JK: We are shooting several videos. And we're doing a bunch of Flash ads for the Newsday.com website. Again, we put those Flash ads and videos into the Cumulus digital asset management system and when a sales representative is out on the road visiting a client, they could use the Web browser to tap into the system. They could then download the video and show it right at the client's place of 
business. Or they could show the Flash ad and say, 'This is what your cube ad would look like on Newsday.com.' Very exciting thing!

I think it gives us an advantage over the competition.

\section{EMERGENCE OF FULL-SERVICE AGENCY WITHIN NEWSDAY}

MM: If I understand you right, James, many of these changes that you've described show that Newsday, in particular, and perhaps publishers in general, will become full-service marketing and creative agencies.

JK: Yes. I have found that to a significant and increasing degree.

MM: And that technology allows the agency function to exist as a node on the network. Depending upon where you have an account executive, you've now got the ability to deliver creative and production services without necessarily having a lot of mortar and brick.

JK: Yes. I'd agree with that, Michael. I think that's very valid.

At the end of the day, it all comes down to the creative and how happy the creative makes those clients. But certainly the technology and getting that creative to the client in a very timely fashion - with good interaction and good visuals - is certainly helping us tremendously.

\section{ALL ABOUT GREAT CREATIVE AND EXECUTION}

MM: That gets to an underlying theme of what it takes to produce great creative. Oftentimes, people operate under what I think of as a misconception: creative is some guy off in a corner with a ponytail and a Mac making up something that looks cool and in a flash of insight goes, 'Ah! That'll work!' Then, they storyboard something and off they go to the client and sell it.

More often than not, you start off with a germ of an idea that might become something. Then come communication, collaboration and interaction with a whole bunch of different people, including the quantitative side of the house that's looking at analytics (customer demographics and trends like that) retail or website traffic reports with the questions of what kinds of people show up, where and when.
Out of this kind of really rich 'soup' of communication and interaction comes a creative product that reflects not only a good marketing focus, but also a way of really engaging very specific customer groups as influenced or directed by the retailer or brand marketer.

So communication and collaboration tend to be much more a part of great creative. It's only exacerbated or multiplied by the question, 'How do I get great creative into print and online?' JK: Yes. I agree with everything you say, Michael. I think in the future, this will be taken to new levels of collaboration.

Using some of the Adobe tools and using Canto Cumulus as a DAM system, I've noticed that the collaboration - in my opinion - has gotten much better.

So think about it. You don't have to take paper proofs of a concept or a storyboard to an advertising director or the AE. You might just shoot them a link that ties back to the Cumulus database, and they'll look for it themselves and annotate it themselves.

That type of collaboration is only going to become greater and greater as the tools get more sophisticated.

\section{USING DAM TO STIMULATE CREATIVE COLLABORATION}

MM: My wife has a business in which she coaches solo practitioners and owners of small professional and business services. Specifically, she has really mastered the art of how to market yourself as a provider of personal or business services - from real estate brokers to life coaches to massage therapists. Her work makes it clear that many businesspeople become paralyzed in terms of, "How do I really create engaging multimedia content that expresses my vision, values, what I offer that stands unique and valued?' This just goes to the fact that creating engaging multimedia content constitutes hard work, and few have mastered it.

James, the mission for your creative service and production shop means that you think about how to improve the creativity of your group's work in print (which is the core of your business) as well as the online and broadcast portions. Would you take us through some of the changes that you've encountered in the creative process, its tooling, and, perhaps, the workflows of how to manage the 
multimedia dimension of a lot of creative and production?

JK: Sure. Well, let's take a step back three and a half years ago. A creative services artist would do a special section for - let's say - breast cancer awareness. It would be done in print, in a vacuum. It would be stored and backed up on $C D s$, and put in a cabinet.

So the next year when someone was looking for it, you'd have to sort through all the CDs, think about who did it, and maybe you could find it in an hour because there were another 200 CDs in there, and they weren't labeled properly, etc.

Fast-forward three and a half years. A lot has happened!

Now, when you're doing that breast cancer awareness section in Adobe InDesign, I think we're just starting to create this mindset where, as you're doing the section for print, you're thinking about, 'How can I bring that section to life on the Web?'

'The components and the elements that I'm using in print - what else can I do online that can't be expressed in print?'

For example - maybe there are some statistics on breast cancer awareness that tie back to a database. Maybe we incorporate videos in the interactive piece. So we're using tools like Adobe InDesign and the Creative Suite to help us do that.

Up until a few months ago, you'd have to do that section in InDesign, and you pretty much had to think out of the box and start all over again in Flash. Now Adobe InDesign allows you to export the InDesign document to Flash, and take your work and make it come to life on the Web. We're extremely excited about that.

The digital part of this is you're working and creating, using these wonderful tools, and on the DAM side, it can go into a DAM like Cumulus where not only can the artist and their colleagues see it, and if the managing editor wants to see this and look at it from her desktop - to make suggestions? It's all right there.

That's an area where I told you it would take 2 hours to find a CD or a DVD from a couple of years ago. Now if you type in metadata that has 'breast cancer awareness,' you'll find the needle in the haystack in seconds, literally.
These are some of the things that we're thinking about with taking that print content and repurposing it for Newsday.com.

\section{DAM WORKFLOWS BREAKING THE WALL BETWEEN PRINT AND ONLINE GROUPS}

MM: I'm sure that you've seen that in the process of thinking through, 'How do we repurpose things,' many of those ideas or notions filter back into the actual creative process, so you create multi-purposed assets from the get-go, as opposed to trying to shoehorn a print asset into a Web space. JK: Outstanding point. I believe that the messages and the way you grab people's attention on the Web is very different from print. I have to confess that I don't come from a creative background - I come more from a production background.

But what the artists are telling me is that just the ability to take those elements from InDesign and port them into Flash ...

But you're right. The main point you were making, Michael - I agree with this. At the point of creativity and as they're conceiving these ideas, they're thinking about that at that time. At least this is our goal - that they think about that, at that time.

The other thing I wanted to mention is that many places have walls between the print folks and the interactive folks. We broke down those walls several years ago, and I made a bet on the future of DAMs and on the Adobe Creative Suite.

I told the company, 'Let's take those walls down,' because the artists will be able to repurpose their content for the Web. It's all coming together now. It has. Yes. This is the way. You're exactly right. The artists are thinking about this at the time of creation.

\section{IMPROVISATION BY EXAMPLE}

MM: It seems to me that having a gallery of multimedia assets in front of a creative person stimulates all kinds of ideation - 'what ifs' and 'how abouts' - that almost train or install by example the need to create in a multimedia and multimodal communications and engagement context.

JK: The creative artists, in a way, you could say they had some of these galleries in the past when you talk about stock art and about these 
various websites for purchased content. But now they have a whole new thing to look at.

They can look at the messages created by their colleagues by using Adobe Flash, and the points that are driven home, and the way those messages are composed. They can collaborate and be inspired much more easily than in the past, without DAM.

In the past, I guess you'd have had to walk over to that person's computer and strike up a conversation to see what they were working on. Now it's in front of their fingertips. They're literally in the DAM all day long, putting their work there or retrieving it.

I think it is inspiration. They do view each others' work much more often now.

\section{DAM-ENABLED WORKFLOWS SUPPORT FIELD SALES}

MM: This calls attention to another core concept of creative support DAMs: optimization for creative workflows and work-in-process files - as opposed to repository and distribution DAMs optimized for central management and access-control functions.

In particular, DAMs that work well in creative and work-in-process workflows tend to have a pretty well-behaved Mac and PC native client by which to really do very fast, fluid drag and drop. Things like Apple scripting or other forms of scripting, so as to automate a lot of the oft-repeated activities and tasks associated with opening a file, resizing it and so on.

Could you take us through some of the finer points from a production/technology or workflow perspective - some of the finer points of the Canto Cumulus DAM solution?

JK: When you receive the Canto DAM, in the beginning, it's very overwhelming when you start to think about workflow and how you want to lay things out. But I learned a long time ago to get the creative folks involved from the beginning - to allow their input.

They can be a very demanding, intelligent group. They want the best. I feel partnering with Vince DiPaola and Moksa, we put some serious demands on the system. We built a workflow that they not only accepted, but they like much more than anything they've had in the past.

Part of that is because the Canto solution is a very visual solution. The Cumulus software works very well on the Macintosh. The collaboration we did with Vince Di Paolo - Vince comes from that background, and that helped a great deal.

We use the KISS method, Michael - Keep It Simple Stupid - but to create a sophisticated workflow.

So what do I mean by that? The artists populate a database themselves. They are responsible for entering the metadata. The artists know that the metadata they enter is critical to the database, and to all of their colleagues searching for that asset 1 week or 5 years from now.

Vince helped us come up with a solution to get that metadata associated with the assets very quickly. In essence, you drop an asset into a certain category. The metadata window pops up and you answer a few simple questions. That asset - again - is in the database forever. We don't plan to purge it at all.

From there, we looked at all the different file formats that we had - whether video or Flash or InDesign. All the image types we have, Michael. Everything behaved fairly nicely.

Then we had the curious challenge of 'How do we get all of the InDesign print documents and the Flash files and the videos to the sales assistants without overwhelming them with file types that they don't need?' That's where Moksa came in and we did custom coding and some advanced workflow automation.

We actually have a flag that the artists can change on a print document. It will take that document, and in the background create a PDF and send it to the Web catalog for the sales associates.

PDF is a word that they understand, and that they can show to a client when they have their laptop out in the field.

The solution I have found, with the right partner on the support side, can be very scalable. It's a system that you can mold and make what you want to make it.

When we started, I thought maybe it would just be a DAM. Now it's turned into an actual workflow solution for us, as well. The artists are much, much happier with Canto and Cumulus than with anything we've had previously. I think a lot of that has to do with the fact that they were involved, and that the Canto solution is a very visual solution.

On the 19th of this month, Star Advertising will begin the process of migrating their current 
solution to Cumulus. This will entail a great deal of custom coding and XML migration from the content server.

\section{PROCESS INNOVATION FROM THE BOTTOM-UP}

MM: If I were to summarize, one, you had a technology that integrated seamlessly with Mac and PC users.

Two, Cumulus accommodated all the file types and media formats that you use and has plugins and a developer community to address new or specialized file types.

Three, you and your consultant, Vince, got involved upfront with the creative and production staffs, getting them to participate in creating customized look and feel dashboards - things that reflected the elegance and efficiencies that they've come to appreciate, and demand from tools like the Adobe Suite and the Mac platform.

Four, over time you began to add new automated tasks, services and capabilities, using scripting and the functions of the operating system - as well as plugins to the end-user client or DAM server. Basically, you evolved into a pretty complex and powerful workflow that continues to evolve one small innovation at a time. Now, you have a pretty sophisticated ecosystem and a platform that supports very complex multi-dimensional workflows.

JK: Yes. I think you covered all the points. There's no need for the organization to try to do this thing and try to customize it and script it right out of the box. You can start small and evolve a little bit each month - over a year's time, it really adds up. And we don't shock the user community with big changes. We're closing in on a quarter million assets - and we started in July of 2007.

MM: How many users and assets do you have now?

JK: We have probably over 200 users, a quarter million assets, and I'd say we average 100 assets per day. But we can certainly put 600 or 700 on a busy day. We could hit 1000 new cataloged assets on a very, very busy week, between all the different departments especially over the Christmas holidays. We support videos and Flash and PDFs and Photoshop files and InDesign files. Every file type that Cumulus supports. My groups are under strict instructions, 'If you touch it, it goes into Cumulus.'

\section{THREE WORKFLOW AUTOMATION PHILOSOPHIES}

MM: Let's get your take on three basic philosophies for workflow. First, we have the top-down, complex and expensive policymanaged routing systems that can model and automate for complex enterprise-wide workflows. Second, you might have a pre-baked workflow system that says, 'Here is a procedure.' It's a matter of turning on and off switches, configuring a pre-baked workflow system. You see a lot of those in traditional DAM systems, where basically I'll call it 'workflow light.'

The third workflow philosophy that we find in Cumulus says, 'We're going to work bottomup with individual users and say, 'What does this particular user need in terms of access, metadata and automated activities?' This might entail installing embedded Java plugins (EJaPs) to the end-user client or server-side equivalents of embedded server plugins (ESPs).

This third workflow philosophy enables you to optimize the productivity at the level of activities and tasks for individual users from the server's entire classes of users or the whole operation.

Would you amend or expand upon any of that?

JK: The only other thing I would amend on that is certainly, I always like to keep the IT professionals in the loop, as well. They weigh in on certain items that will help and protect our organization, as well on the way things should be engineered and how best to do it - not only for the users, but also for the organization.

But yes, you hit it very well, Michael. Very accurately.

\section{IT SUPPORT OF DAM SYSTEM}

MM: Would you speak to your IT infrastructure? How has it grown since the inception of your Cumulus DAM, in terms of your network topology, bandwidth requirements, storage, servers and stuff like that? JK: That's an interesting story. The Canto Cumulus solution was originally purchased as a small workgroup solution for the small group of artists.

MM: As many are!

JK: It's a wonderful solution. I'm sure it works fine. 
Strategically, it didn't take long for us to see that it could be much more than that. It could not only support all of our internal folks advertising included. We wanted to take it outside and have the folks tap in with the clients, out on the road, and keep the feet on the street.

When you go from a small workgroup solution, of course, to a pretty big enterprise version solution, when you start talking about hundreds of users on the system, we needed a good partner to support us. Then of course the IT structure came in to place.

We started, Michael, with one Windows server that was running both the Canto Cumulus solution and its Web services on the same exact box. MM: This was a 4-wide Dell or Compaq type box?

JK: Yes. Exactly. It's going to the point now where the whole solution is being ported to Linux. Full disaster recovery.

MM: That would be like a RedHat Linux? JK: That's correct. And a separate Web server. MM: And you're running on probably the same kind of Intel box? Or are you moving? JK: Yes. I believe it's that same type of Intel box. It's going to be high availability and recoverable, etc, etc.

I guess the plans for the future could even be porting it to Solaris. The IT folks here are certainly comfortable with all of the solutions between Windows, Linux and Solaris. But they felt that the best solution for now was to go with Linux. They want the user to have the best experience.

Another thing I've learned many years ago, Michael - sometimes with the users, the advertising folks, etc. You have one shot to grab their attention and to get their buy in. IT plays a role in having the system perform well and help you with that. Certainly, your support vendor like Moksa plays a huge role in that as well. MM: So right now, you have 200 users and a quarter million digital assets on one 4-wide Dell server or Compaq server?

JK: Correct.

\section{HUGE FILES ACROSS CORPORATE NETWORKS}

MM: So daily production workflow would then include pulling many large files across the network. How did you accommodate that?
Do you have a separate network over which you pull these files? Or does it take place on your basic corporate network?

JK: It's the basic corporate network. And I'm glad you asked that question, because I do want to share something with the readers.

The basic core network is $100 \mathrm{mb}$ to the desktop. It's nothing super-super sophisticated.

I was fortunate enough to get some Intel Macs last year, and we did notice that the ingestion of the assets and the calling of the assets out of the database did seem to perform better on the Intel Macs as opposed to maybe some of the older G5s.

This is because of the engineering effort made by Canto in Berlin. The Cumulus client is designed to handle much of the workflow processing itself, only going to the server to write metadata or draw out info and assets when required. So, the more powerful the workstation, the better the performance.

The users are very picky in many cases, and performance has never been an issue. We do embed all the high-resolution artwork in the InDesign documents that we store in the database. But when the users call them out, I haven't heard any complaints about things taking too long.

So clearly, the architecture of the system must be doing something right because we don't have complaints on that end. And the searches too, Michael - finding the assets.

MM: Yes. That makes sense. You're just hitting metadata and thumbnails at that point. Right?

JK: Yes.

\section{FILE-DELIVERY SYSTEMS}

MM: Let's step outside the firewall of your advertisers and field organization. Do you use any kind of special bandwidth optimization or asset-delivery systems? Low-end systems might entail services YouSendIt, and at the high-end, services from (Radiance or Aspera) or other kinds of bandwidth optimization systems.

JK: No. We have not.

MM: Is that something that you anticipate being an issue? Or does it seem that everyone's fine with their basic HTTP connections and FTP servers? 
JK: I think it's a topic that will need to be explored, especially as the system grows. But as of right now, Michael, it doesn't seem to be an issue.

\section{CAREERS IN DAM OPERATIONS}

MM: Perhaps you can speak to some of the more human and/or professional dimensions of a DAM practitioner? You led off today talking about your 19-year career and working your way from the bottom-up. Now you have 150 or so people reporting to you.

If you were advising or coaching somebody that was 28 - or 32-years old today, and who asked you, 'Hmm - what's this DAM thing?' And, 'What are the career upsides for that?' What do you envision as necessary skills that someone should possess in a DAM-related environment?

Also, what other kinds of jobs should an innovation leader such as yourself think about having under his or her belt that would prepare him or her for the current and anticipated future of advertising and the publishing business?

JK: To the first point, I'd say to spend time on workflow. It generally will always come back to help you. Listen carefully to your users and get multiple opinions.

MM: By that, James, do you mean getting an academic or a structured education/ orientation around definition and modeling of workflows?

JK: I was thinking more of a hands-on approach and using flowcharts to map things outto clearly understand every step of the workflow.

Secondly, if you want to get into DAMs - and I see them just growing and growing and becoming more and more prevalent - think about the DAM as more than just what you need it for. Try to think about how it may touch every department in your organization and how you can help those departments.

I've mentioned several times today that all of the creative and production folks are on it. And the advertising folks. I didn't mention that the marketing team at Newsday - as soon as they heard about Cumulus - wanted in. So we said, 'Sure. Why not?'
When the Pennysaver or Star Community Publishing wanted in, we said, 'Sure. Why not?'

So think about more than just your local department. That can go a long way in helping the company and your career.

\section{SKILLS OF DAM PROFESSIONALS}

MM: Are there any other particular technologies or other kinds of complementary skills that a DAMster should have?

JK: I think a DAMster should have as much knowledge about Adobe's Creative Suite as they can obtain. I know that's a very broad statement. There's so much to extract from the Creative Suite.

But what I've seen over the past several years, I think a DAMster could really benefit from learning as much as they could about Adobe's Creative Suite and Adobe's future direction when analyzing the Creative Suite.

\section{ADOBE CREATIVE SUITE AS A CAREER PLATFORM}

MM: Adobe's Creative Suite has evolved beyond just a set of tools and technologies. The Creative Suite has become a career platform - a toolset for innovating new workflows and processes, as well as career and business opportunities.

JK: I couldn't agree more. I think from what I've seen, that trend will only continue.

MM: Would you speak to becoming more skilled in the particulars, not just of the Creative Suite, but how to engage and thrive in the whole ecosystem of tools, technologies and plugins that fit into that?

JK: Yes. Think about how those tools could possibly overlap in the future. I'll give you an example.

In Flash at one point, you might need to know how to do some coding and scripting and what not. I envision Adobe pushing more of that work back to the designer. When the designer creates, the code will somehow be generated in the background. And maybe that piece as a whole gets passed off to a developer, to a client, to a database, etc, etc.

Adobe is going to make it easier and easier for creative types to do more exciting, innovative work as we progress out. 


\section{CREATIVE WORKBENCH WITH DAM}

MM: We've seen in the new Creative Suite 4 that Adobe added a whole bunch of tools for Web, print and multimedia. In one respect, the creative professional no longer works in the isolated ghetto of just a print or an online group. Rather, the creative professional has emerged as a multimedia, multimodal communications specialist.

JK: Yes. And the one thing they're missing is a DAM to organize all of that for you.

They don't do workflow, per se. Combining the two can really help your organization tremendously.

\section{FUTUREPROOF}

MM: Fabulous. Would you have any final summarizing statements for DAM and related systems at Newsday?

JK: Yes. I would say in everyone's busy work career, sometimes we get so caught up in the day to day that we don't have time to think strategically about the future. Think strategically about a DAM and how it can benefit your organization, and you won't be sorry.

MM: Okay! James, I want to thank you very much for the time that you've spent with us. Great success in terms of continuing to drive process innovation into Newsday.

JK: Thank you, Michael. It was my pleasure. 